\title{
Influence of Implemented Courseware on Students Knowledge Acquirement
}

\author{
Constantin-Gelu APOSTOL, Alina-Mihaela ION, Dragoş VESPAN \\ Department of Economic Informatics and Cybernetics, \\ The Academy of Economic Studies, Bucharest, Romania \\ apostolc@ase.ro, alina.ion@ie.ase.ro,dragos.vespan@ie.ase.ro
}

This paper presents the implementation of the courseware stages developed for an economic faculty with teaching in foreign languages with learning on campus through an assisted instruction approach based on a collaborative platform. The implementation of the conceptualization, construction and dialogue stages on the university platform dedicated to students in the first year is explained. We analyze the correlation between the accesses of didactic technologies on the educational platform and the results obtained at the final exam in order to see how the implementation of courseware technologies influenced the knowledge acquirement by students.

Keywords: Assisted Instruction, Collaborative Platform, Courseware Approach Stages, Pearson Correlation Coefficient, Coefficient of Determination

$\mathbf{1}^{\mathrm{I}}$ Introduction

All domains of activity benefited from the evolution of information and communication technology which had a significant impact on them. This also influenced the educational domain, especially on the professional preparation of the new generation ready to integrate in the labor market. Using information technologies in education actually pushes the transformation of the classical classroom into an eclassroom. This environment for deploying didactic activities is primarily targeted for distance learning in a virtual class, called eClass, where students have their own learning peace and their own style to study educational materials and where it is not possible for them to meet periodically in order to attend the traditional classes. Related to classical teaching, learning and assessing activities,[1] defines the e-Classroom as an extension of the traditional classroom in a technological infrastructure based environment, where computer assisted instruction and teacher assisted learning are components with the purpose of ensuring basis and professional competencies as an optimal condition for lifelong learning. The main feature of such kind of approach is the classwork, as a connection between content and the infrastructure technology.
In order to provide support to the instruction process, a huge amount of materials for courses and seminars have been developed over time. As ICT (Information and Communication Technology) was intensively used for creating such educational materials, "intelligent courses" dedicated to students, known also as courseware, were developed. The concept of courseware has the same structure as other terms consecrated in informatics, like hardware (the physical part of computers), software (represented by operating systems and applications) or firmware (base software personalized embedded inside a hardware device), [2].

The development of courseware aimed at enriching students' knowledge and at developing their skills, with the focus on how to structure, present and transmit information during the instruction process. When used to create courseware, ICT represents a means of doing it and not an end in itself.

In order to reach an educational objective, the design of the course is more important than the technology used to create it. Also, it is very important to take into account that technology does not mediate the learning process but rather the knowledge is meditated by the thinking processes induced by technology [3]. 
Courseware includes materials for the courses mediated by the instructor or by the professor, materials for self-instruction, interactive tutorials, and support materials for distance learning which eliminate geographical barriers due to Internet connection, bidirectional synchronous or asynchronous digital communication between students and instructors. This didactical technology is based on the studentcomputer interaction or on instructorcomputer interaction [2].

\section{Practical Approaches}

Courseware didactic technologies vary from educational support presented as simple text to the more and more efficient interactive support created using the latest information and communication technologies.

In the author aims to establish a parallel between the organizational models and the didactic architectures used by businesses to manage internal training. In this context, the author describes the elements which constitute and characterize the four didactic architectures identified in the research (see

Table 1).

Table 1.Didactic architectures based on information and communication technologies

\begin{tabular}{|c|c|c|c|c|}
\hline $\begin{array}{c}\text { DIDACTIC } \\
\text { ARCHITECTURE }\end{array}$ & $\begin{array}{c}\text { WEB BASED } \\
\text { TRAINING }\end{array}$ & ELEARNING 1.0 & $\begin{array}{c}\text { ONLINE } \\
\text { EDUCATION }\end{array}$ & ELEARNING 2.0 \\
\hline $\begin{array}{c}\text { Theoretical } \\
\text { Framework }\end{array}$ & Behaviorism & Cognitivism & Constructivism & Connectivism \\
\hline $\begin{array}{c}\text { Pedagogic } \\
\text { approach }\end{array}$ & $\begin{array}{c}\text { Transmissive } \\
\text { (autonomous) }\end{array}$ & Assisted & Collaborative & Peer to Peer \\
\hline Tools & Web-delivered & LMS & $\begin{array}{c}\text { LMS + collaborative } \\
\text { tools }\end{array}$ & Web as a platform \\
\hline Contents & $\begin{array}{c}\text { Course-based } \\
\text { training }\end{array}$ & Learning objects & $\begin{array}{c}\text { Mixed production by } \\
\text { teachers and } \\
\text { students }\end{array}$ & $\begin{array}{c}\text { Community based, } \\
\text { user-generated } \\
\text { contents }\end{array}$ \\
\hline
\end{tabular}

In order to increase the performance of students in the first year of an economic faculty with teaching in a foreign language, the professors that teach courses and seminars in informatics developed educational materials specific to courseware technology. All the supports were uploaded on the university platform dedicated to students.

Students can access the materials by getting authenticated through a username and a password they received when they signed up on the platform.

The need for using this technology raised from the variety of the 100 students admitted every year by the faculty. About $25 \%$ of them come from other countries as a result of the specific learning system of origin country where they benefited from different teachinglearning-assessment methods. Although they belong to the same country and they reflect the result of the same educational system, Romanian students come from different learning institutions, with different teachers and different conditions provided for the deployment of the educational process. The study was made for the students admitted in the fall of 2011. Out of the 77 admitted students, $21 \%$ are foreign students coming from francophone countries and the rest of $79 \%$ are Romanian students.

The use of courseware technology aimed at the development of a complementary support that assists the traditional learning with campus presence by covering the requirements of a large number of students, by stimulating collaboration and by eliminating barriers raised by the differences in students' education.

\section{Stages of Courseware Specific Model}

The specific model for courseware development was used as a paradigm of the university platform during the instruction process. This model includes three stages: conceptualization stage, construction stage 
and dialogue stage [5], and it is based on the description of the basic unit of conceptual learning as a cycle.Professors teaching informatics developed and used primary, secondary and tertiary courseware didactical applications, according to the stages of the model showed, as soon as this account can be mapped onto type of learning technology [6].

\subsection{Conceptualization}

In the conceptualization stage, when the presentation of the content occurs, students get in contact with the disciplines they will be taught and, practically, with the concepts proposed by the professors. Students get also familiar with the domain and with the study method.

This stage is based on using primary courseware approach. Generally, primary courseware should be designed by experts in instruction. Practically, most of the times, it is designed and developed by experts in courseware educational material development.

For the study case, primary courseware provides students, through the educational platform, with educational materials, videotutorials, bibliographies, Internet resources that present in detail the current instruction sequence.
Course/seminar supports are developed according to pedagogical methods and practices, taking into account simultaneously the study methods preferred by students. Then, these supports are published on the platform. Each support is firstly presented to the students inside the laboratory class, through teaching/learning methods specific to learning with campus presence.

The publication of the supports on the platform and the recommendation of other educational materials allow students to study also outside classes. The use of these supports during the classes, especially during informatics classes, allows the advanced students to finish quicker the assignments received during the class. Thus, those having difficulties benefit from the full attention of the instructor and the deployment of a personalized instruction process is encouraged.

The supports that are specific to primary courseware are accessed by students during the instruction process in order to clarify concepts not understood, to solve home works, to create projects, to enrich general knowledge or to simply satisfy their curiosity. This way, students develop learning by searching activity, Fig. 1.

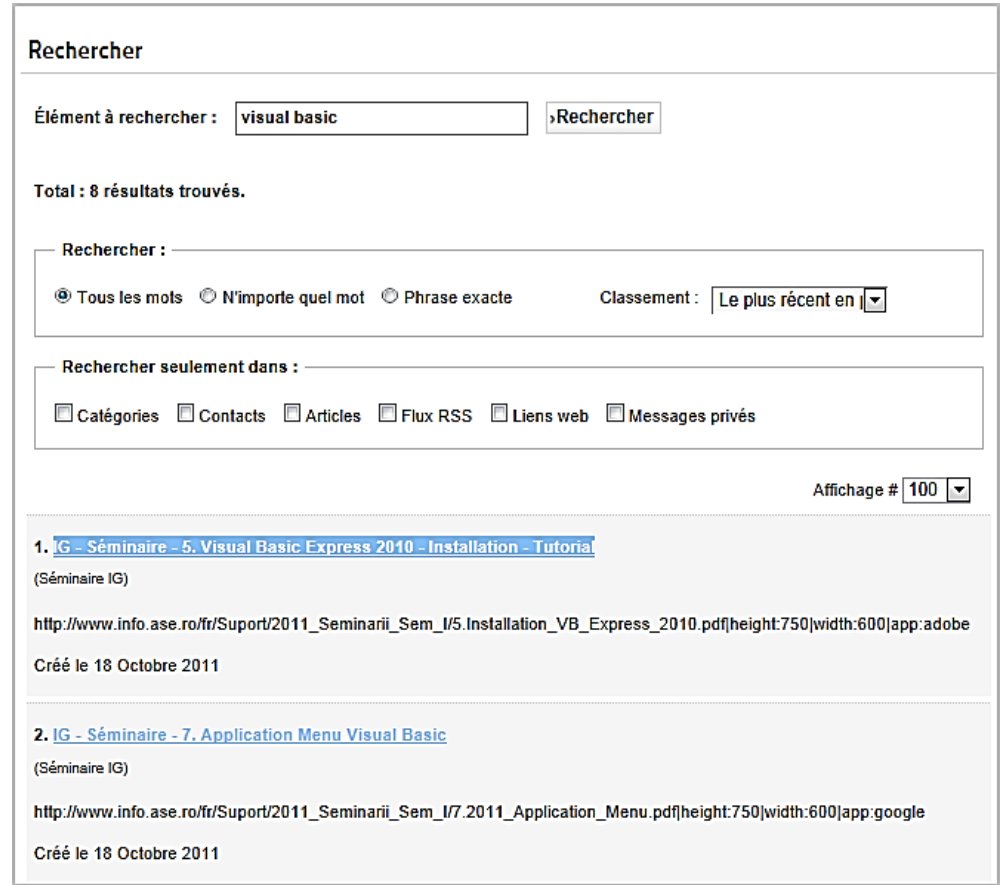

Fig. 1. Search module implemented on the educational platform 
In order for the information that students learn to correspond to the information required at that time, the entire search process is guided and structured by the professor, thus avoiding confusing searches.

The platform takes advantage of a personalized search system through the search module which allows searching only inside course and seminar supports uploaded on the platform. The risk of getting wrong information is considerably diminished [7].

\subsection{Construction}

In the construction stage the student tests his knowledge and accomplishes his learning tasks using the resources provided by the system.

Secondary courseware represents an educational support designed for activities done by the students during the learning process. This type of support can be a new one, developed by instructors specifically for the instruction process, or can be taken and adapted from a primary courseware educational support.

The secondary courseware technology is characterized by providing students with support to accomplish both formal activities, as home works, essays, projects, laboratory projects, and informal activities as notes, material searches and exam practice.

The tools used for accomplishing secondary courseware are available both to instructors and students. These tools are equally efficient if they are made available to both professors in order to deliver materials and to students in order to create their own materials.

Students deploy activities for collecting information, filtering, organizing and explaining it in order to accomplish home works and projects assigned at informatics classes. In many situations, the latter may be also considered to be educational material that is quicker understood by those who read it. The entire process simplifies and encourages learning more than the classical reading of materials developed by instructors. Due to evolution of ICT, students have the same access possibilities as instructors for using text processors, graphic representation tools, content creation modules, videoconferences, to create educational materials that will be made available to colleagues to answer their questions on forums, to fill in questionnaires or to accomplish home works and projects [8].

The results of this process vary in quality as they depend on the background of the student that created them, on his structuring, understanding, defining and expressing skills. At this level, students may access both the tools required for accomplishing learning tasks and the instruction platform with all its features.

In order to identify the concepts that raised questions during the instruction process, a Wiki module was included on the platform. It has the role of an explanatory dictionary for terms, concepts and methods presented at the course and seminar classes or in the recommended educational materials in informatics field.

Although the Wiki module is administered by professors (instructors), the educational content is created by collaborating with students. The instructor is the one that integrates inside the module the information presented during course and seminar classes. Students have rights to view this information but they can also express their interest for other information that cannot be found inside the Wiki module. Students are thus encouraged and stimulated to actively participate by adding information from the domain that is currently studied. Also, they have editing rights in order to complete certain information or to correct possible mistakes. Before the final publishing in the Wiki module, all the information that students contributed to is verified by the instructor. Thus, the information added to the module becomes public only after the instructor approves it. The risk of students getting wrong information through the search process is diminished this way, Fig. 2. 


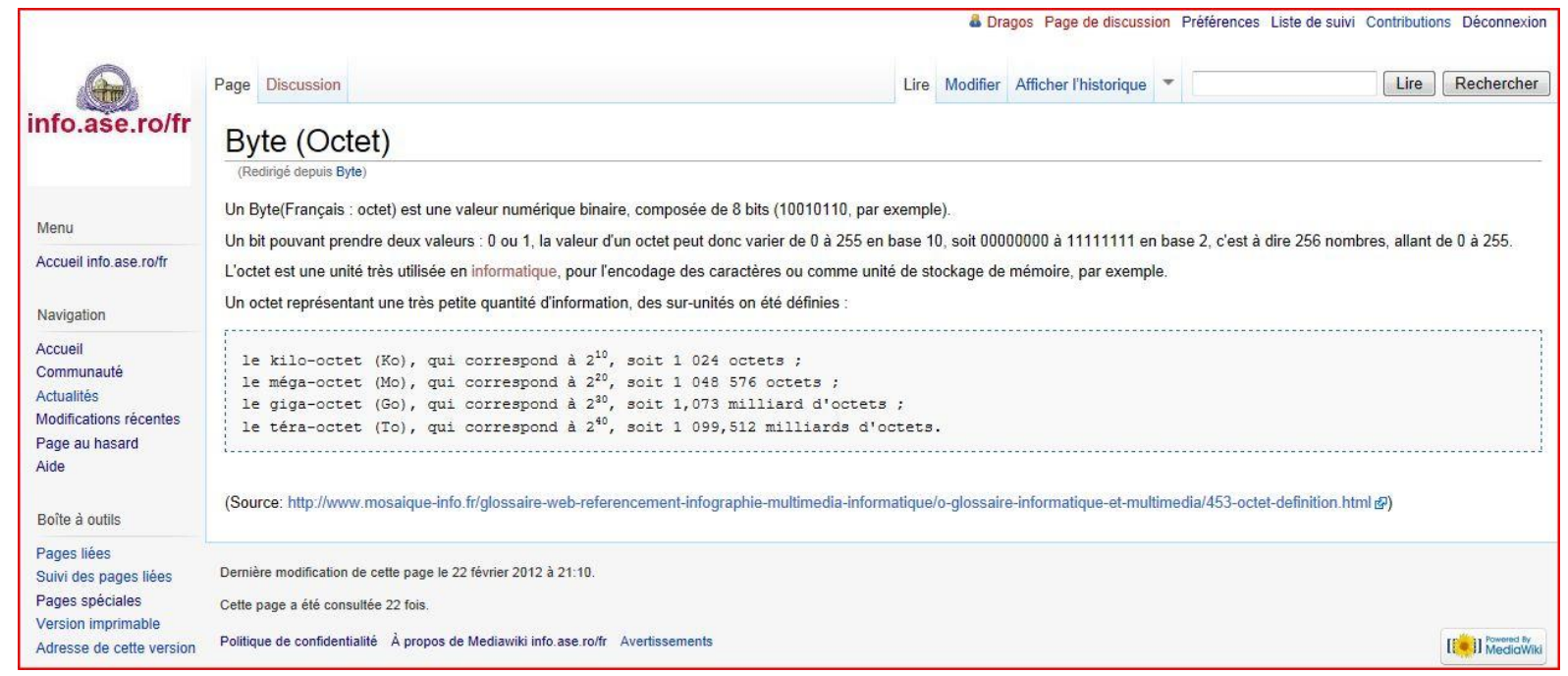

Fig. 2. Wiki module on the educational platform

The platform provides the students with access to a discussion forum which is used for requiring information about accomplishing seminar home works and projects.

Questions regarding home works and projects may be written and posted on the forum by a single student, but the answer will be useful to more students. Vicarious learning (learning by observing) is encouraged this way during the learning process.

Alike the Wiki module, all the information, questions, answers, attached documents and Internet resources published on the forum are firstly validate by the instructor in order to avoid publishing information or materials with inadequate or wrong content.
For accomplishing the formative evaluation of students, a knowledge testing module is also included on the platform. This module allows students to auto-evaluate the knowledge they acquired. For each instruction sequence or module, test batteries are created for both the formative evaluation and self-evaluation of students [9].

\subsection{Dialogue}

The dialogue stage promotes the dialogue and the communication. Practically, this is accomplished when the student receives an answer regarding his performances and tries to clarify, through dialog with the instructor, the concepts he didn't understand. Also at this stage, the student creates a new conceptual frame or improves a previous created conceptual frame.
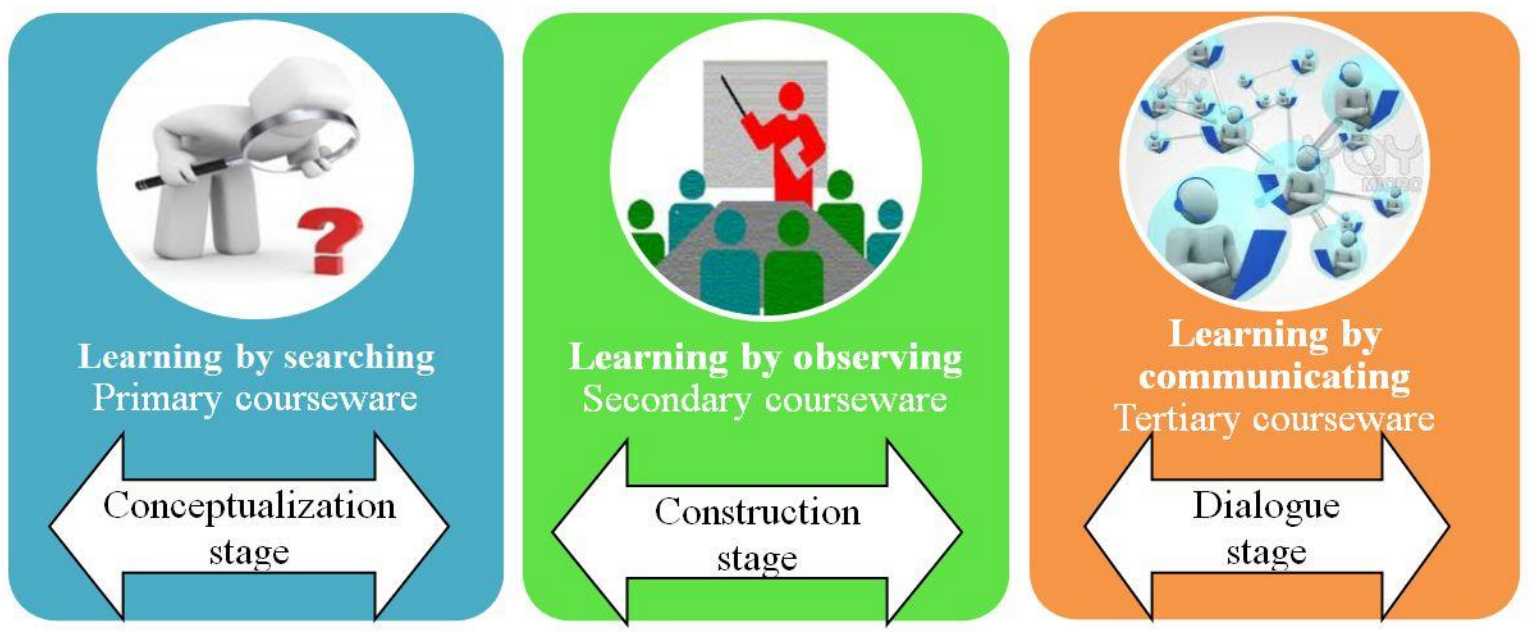

Fig. 3.The three activities in a learning process courseware based 
Tertiary courseware is an educational support represented by educational materials and by the discussions of students from previous promotions. This category includes the discussions left on the forum and available to new students about the subject of the instruction, the results obtained after the evaluation, or about various educational materials created by instructors or students, discussions which took part between the students or between the students and the instructors. This stage encourages the learning by communication with other students interested by the same object of study.

The three types of learning supported by courseware are represented in Fig. 3.

The discussion forum available to students through the educational platform allows a permanent communication between students and between students and instructors. Identified problems are discussed and analyzed again during traditional meetings, in the classroom.

The forum is generally used by students that require information about accomplishing a home work or a project. The information left on the forum, the answers to the questions, recommendation and suggestions, the concepts defined in the Wiki module, the course and seminar supports created by professors, instructors or students, all of these get transformed into educational materials for future promotions or for anyone else accessing the platform that considers them to be useful. The information published on the platform encourages the dialogue between all the actors implied: students, professors and instructors. Given the recursive nature of the learning process, new subjects proposed for debate may be analyzed by instructors in order to create new educational materials for all the three types of courseware.

In order to encourage the dialog in real time, a chat module was also included into the platform, Fig. 4 similarly to the module provided by Facebook, for private discussions between online users, be they students, professors or instructors.

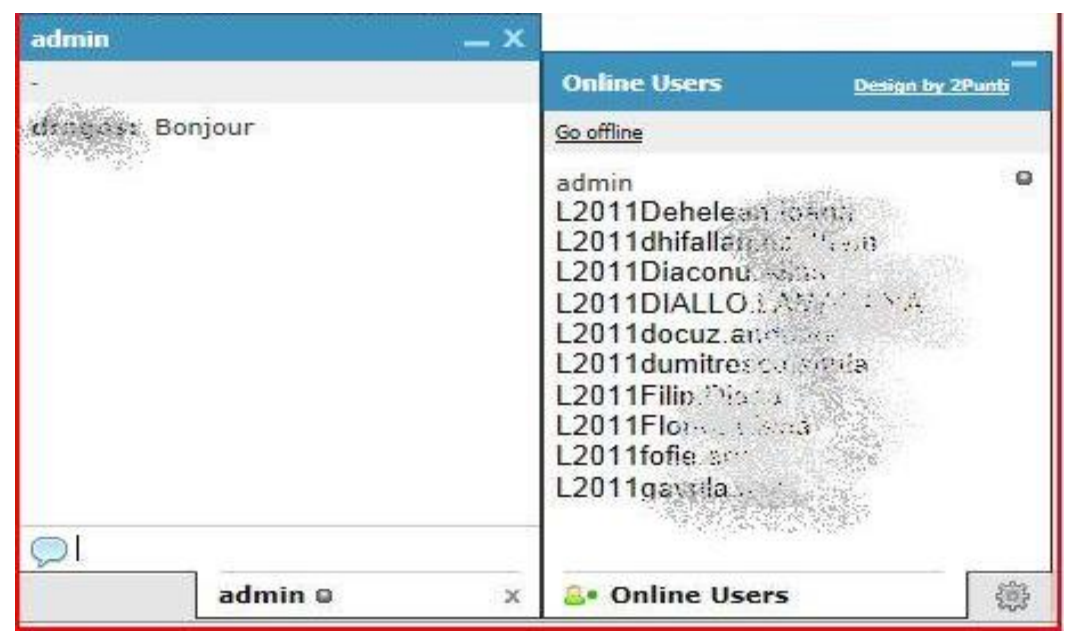

Fig. 4. Chat module

For asynchronous communication, a module for sending e-mails between the users of the platform was also included. Through this module, users can send both written text and attached documents.

The learning process was simplified because of communication done through question asking, answering or discussions as exchange of opinions.

The result of this operation is transformed into materials for a new conceptualization stage, in fact a re-conceptualization stage that highlights the recursive character of the learning process, Fig. 5. 


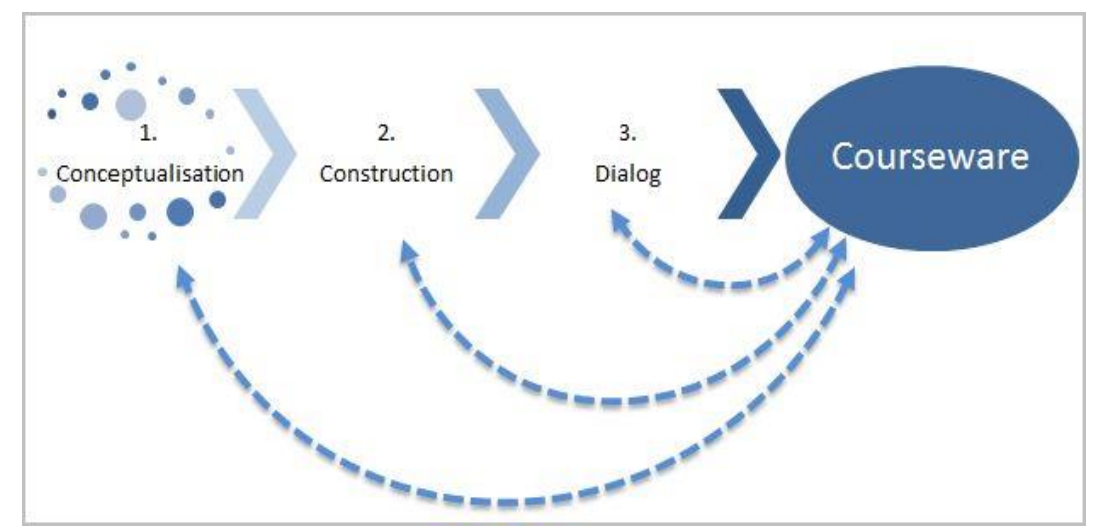

Fig. 5. Stages for creating courseware educational support

Tertiary courseware didactical technology represents a mean to concretely support the learning process. It is centered on communication and uses technologies that facilitate communication. This type of support offers to students learning at distance the sense of belonging, of integration into a study group in the same domain of instruction. Students that study in classical form, with presence on campus, through the means of distance communication are also encouraged to communicate and to accomplish social and collaborative activities[6].

\section{Results Analysis}

In order to successfully accomplish the instruction process, the three types of courseware technologies have been used simultaneously. The 77 students admitted in the fall of 2011 which attend daily courses with presence on campus at the same section of the faculty analyzed, benefited from these technologies through the educational platform made available by the professors that teach informatics.

All the accesses of educational supports by the students have been recorded into the platform database. Results of queries on the database showed information about how each student accessed the content on the platform. These results were analyzed in order to verify the correlation between the variables access of didactical technologies on the educational platform and results obtained by students at the final exam.

In order to determine the existence of a relationship between variables access of didactical technologies and results obtained by students at evaluations, we computed, for the chosen sample, the Pearson correlation coefficient.

From the 77 students, we eliminated those who weren't present at the final exam. Thus, the sample was reduced to 69 students. Analyzing statistical data for these 69 observed cases, we obtained a correlation coefficient between accessing of educational technologies and results obtained by students at evaluation with the value $r=0.369$, Fig. 6 .

\begin{tabular}{|l|r|r|}
\hline \multicolumn{3}{|c|}{ Pearson Correlation Matrix } \\
\begin{tabular}{|l|r|r|}
\hline & NOTES & VISITS \\
\hline NOTES & 1,000 & \\
\hline VISITS & 0,369 & 1,000 \\
\hline
\end{tabular}
\end{tabular}

Fig. 6. Pearson correlation matrix

According to the interpretation of the values of correlation coefficients proposed by [10], as the value of correlation coefficient is greater than the 0.30 threshold, we can deduce the existence of a medium linear correlation between variables analyzed.

Based on the values of the two analyzed variables, we created the scatter plot matrix by representing the values in a $\mathrm{XOY}$ axis system.

The visual analysis of the distribution and of the form of the scatter plot obtained in the graphical representation,Fig. 7, reveals the linear trend which demonstrates a positive association between the variables accessing didactical technologies and results obtained by students at evaluation. 
The coefficient of determination computed on the basis of the correlation coefficient evaluation mark is influenced by the variable identifies the extent to which the variable accessing didactical technologies.

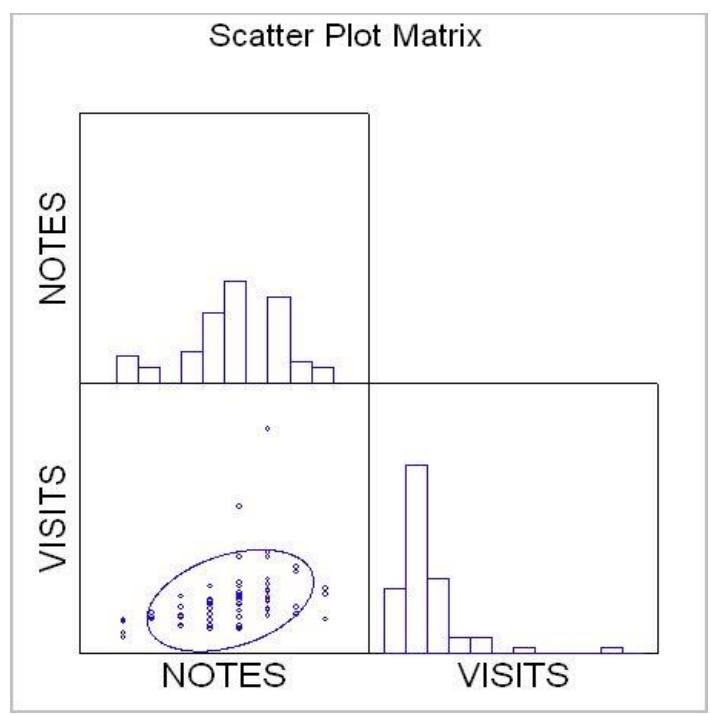

Fig. 7. Scatter plot matrix

As we obtained a significant correlation coefficient, we can also compute the coefficient of determination as being $\mathrm{r}^{2}=0.136161$. We conclude that $13.61 \%$ of the variation of the dependent variable, results obtained by students during evaluations is explained by the independent variable accessing of didactical technologies on the educational platform.

\section{Conclusions and Future Directions}

Based on the results of statistical analysis, we can state that creating primary, secondary and tertiary courseware didactical technologies and publishing them on the educational platform in order to be accessed by the students, regardless their location or the access time, contributed to the achievement of a greater mark at the final exam.

The use of courseware didactical technologies represents an instruction mean which is complementary to the traditional learning, with presence on campus.

In the future we will diversify the ways to present the information in educational supports that make courseware didactical technologies. Thus, they will cover a greater number of students and we hope that their access will lead to the increase of the Pearson correlation coefficient.

\section{References}

[1] G. Zamfir, "The Scientific Research Concept in Assisted Instruction," The Proceedings of the 9th International Conference on Informatics in Economy 2012, pp. 421-427, 2012.

[2] I. G. Roşca, C.-G. Apostol and G. Zamfir, "E-learning - paradigmă a instruirii asistate," Revista Informatica Economica, vol. 2, no. 22, pp. 5-17, 2002.

[3] R. E. Clark, "Reconsidering Research on Learning from Media," Review of Educational Research - JSTOR Collection, vol. 53, no. 4, pp. 445-459, 1983.

[4] L. Gonella and E. Panto, "Didactic architectures and oraganization models: a process of mutal adaptation," eLearning Papers, no. 9, 072008.

[5] J. T. Mayes and C. J. Fowler, "Learning technology and usability: a framework for understanding courseware," Interacting with Computers - British Computer Society, vol. 11, no. 5, pp. 485-497, May 1999.

[6] J. Newman, H. Lowe, S. Neely, X. Gong, D. Eyers and J. Bacon, "A Tutorial Task 
and Tertiary Courseware Model for Collaborative Learning Communities," Electronic Journal of ELearning, vol. 2, no. 1, pp. 159-166, february 2004.

[7] L. Coventry, "Video Conferencing in Higher Education," Sima - Support Initiative for Multimedia Applications, Edinburgh, 1997.

[8] J. Grifoll, E. Huertas, A. Prades, S. Rodríguez, Y. Rubin, F. Mulder and E. Ossiannilsson, "Quality Assurance of Elearning," European Association for Quality Assurance in Higher Education
2009, Helsinki, Finland, 2010.

[9] C.-G. Apostol, A.-M. Ion, D. Vespan and I. Întorsureanu, "Evaluation through assisted instruction platforms," in Proceeding of International Conference on e-Learning and Knowledge Society, Bucureşti, 2011.

[10] J. Cohen, Statistical power analysis for the behavioral sciences, 2 ed., vol. 1, Routledge, Ed., Hillsdale, New Jersy: Lawrence Erlbaum Associates, Inc., 1988, p. (88) 567.

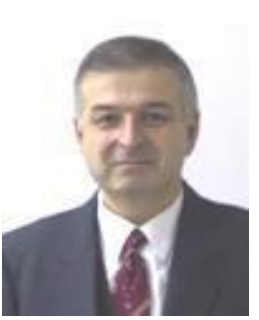

Constantin-Gelu APOSTOL is professor at the Department of Economic Informatics and Cybernetics at the Faculty of Cybernetics, Statistics and Economic Informatics from the Bucharest University of Economic Studies. He has graduated the Faculty of Economic Cybernetics in 1974. He holds a $\mathrm{PhD}$ diploma in Economic Cybernetics from 1980 and he is full professor since 1992. He is the author of 37 books and more than 80 scientific communications. Since 2004 he is the director of Bulgarian-Romanian Interuniversity Europe Centre. He is member of Association for Computer Machinery (ACM) since 2000 and member of Project Management Romania since 2001. He was involved as project director in several major scientific research contracts and his main interests are related to software for assisted training, database applications, design and implementation of dynamic Web sites, design and implementation of Microsoft Office applications.

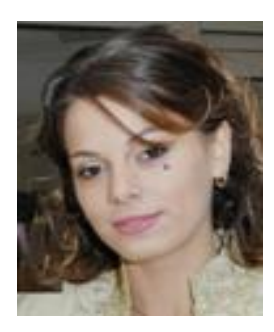

Alina-Mihaela ION graduated the Faculty of Cybernetics, Statistics and Economic Informatics at the Academy of Economic Studies from Bucharest. She has a master in Informatics Project Management and a PhD in Economic Informatics from the Academy of Economic Studies. She is certified as IPMA level D in Project Management by Romanian Project Management Association. Her activity and research focus on e-Learning, assisted instruction, collaborative platforms and Internet Technologies.

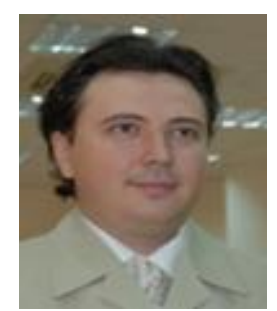

Dragoş VESPAN is Lecturer at Economic Informatics Department of the Academy of Economic Studies from Bucharest, Romania. In 2002 he graduated the Faculty of Cybernetics, Statistics and Economic Informatics at the Academy of Economic Studies of Bucharest and since 2008 he has a $\mathrm{PhD}$ degree on artificial intelligence. Also, he is certified as IPMA level $\mathrm{C}$ in Project Management by Romanian Project Management Association. His work focuses on artificial intelligence, text mining and internet technologies. 